\title{
THE POTENTIAL OF METERING ROUNDABOUTS: INFLUENCE IN TRANSPORTATION EXTERNALITIES
}

\section{Paulo Fernandes, PhD.}

Post-Doctoral Researcher, Mechanical Engineering

University of Aveiro

Dept. Mechanical Engineering / Centre for Mechanical Technology and Automation (TEMA) Campus Universitário de Santiago, 3810-193 Aveiro - Portugal

Phone: (+351) 234378 172, E-mail paulo.fernandes@ua.pt

(Corresponding author)

João Teixeira, MSc.

Research Fellow, Mechanical Engineering

University of Aveiro

Dept. Mechanical Engineering / Centre for Mechanical Technology and Automation (TEMA)

Campus Universitário de Santiago, 3810-193 Aveiro - Portugal

Phone: (+351) 234370 830, E-mail: jpteixeira@ua.pt

\section{Claudio Guarnaccia, PhD.}

Senior researcher in Applied Physics, Assistant Professor of Physics

University of Salerno, Department of Civil Engineering

Via Giovanni Paolo II, 132, I-84084 Fisciano (SA)

Phone: (+39) 089 969356, E-mail cguarnaccia@unisa.it

\section{Jorge M. Bandeira, PhD}

Post-Doctoral Researcher, Mechanical Engineering

University of Aveiro

Dept. Mechanical Engineering / Centre for Mechanical Technology and Automation (TEMA)

Campus Universitário de Santiago, 3810-193 Aveiro - Portugal

Phone: (+351) 234378 172, E-mail: jorgebandeira@ua.pt

\section{Eloísa Macedo, PhD}

Post-Doctoral researcher, Mathematics

University of Aveiro

Dept. Mechanical Engineering / Centre for Mechanical Technology and Automation (TEMA)

Campus Universitário de Santiago, 3810-193 Aveiro - Portugal

Phone: (+351) 234378 172, E-mail: macedo@ua.pt

\section{Margarida C. Coelho, PhD.}

Assistant Professor, Mechanical Engineering

University of Aveiro

Dept. Mechanical Engineering / Centre for Mechanical Technology and Automation (TEMA)

Campus Universitário de Santiago, 3810-193 Aveiro - Portugal

Phone: (+351) 234378 172, E-mail margarida.coelho@ua.pt 


\begin{abstract}
Roundabouts are increasingly being used on busy arterial streets for traffic calming purposes. However, if one roundabout leg is near a distribution hub, e.g. parking areas of shopping centers, the entry traffic volumes will be particularly high in peak hours.

This paper investigated a partial-metering based strategy to reduce traffic-related costs in a corridor. Specifically, the resulting traffic performance, energy, environmental and exposure impacts associated with access roundabouts were studied in an urban commercial area, namely: a) to characterize corridor operations in terms of link-specific travel time, fuel consumption, carbon dioxide and nitrogen oxides emissions, and noise costs; b) to propose an optimization model to minimize above outputs; and c) to demonstrate the model applicability under different traffic demand and directional splits combinations.

Traffic, noise and vehicle dynamics data were collected from a corridor with roundabouts and signalized intersections near a commercial area of Guimarães, Portugal. Microscopic traffic and emission modeling platforms were used to model traffic operations and estimate pollutant emissions, respectively. Traffic noise was estimated with a semidynamical model. Link-based cost functions were developed based on the integrated modeling structure. Lastly, a Sequential quadratic programming type approach was applied to find optimal timing settings.

The benefit of the partial-metering system, in terms of costs, could be up to $13 \%$ with observed traffic volumes. The efficiency of the proposed system increased as entering traffic at the metered approaches increased ( $\sim 7 \%$ less costs). The findings let one to quantify metering benefits near shopping areas.
\end{abstract}

Keywords: Partial-metering, Roundabouts, Modeling, Optimization, Link-based Costs 


\section{INTRODUCTION AND OBJECTIVES}

Roundabouts offer capacity and safety advantages over traditional signalized and stopcontrolled intersections (1). The main reasons for the increased traffic performance and safety levels are due to: $i$ ) low approach and circulating speeds; $i i)$ fewer conflicts points, especially those regarding the right-angle and left-turn head-on crashes; iii) lower crash severity; and $i v$ ) possibility of U-turn without requiring tight turning radii for vehicles ( 1 ; 2).

Consequently, many authorities have been adopted roundabouts in series along corridors $(3 ; 4)$, some of these located near business and commercial areas. Previous studies have demonstrated the commercial, healthy environment and safety benefits of replacing signalized corridors by interdependent functionally roundabouts near commercial locations $(5 ; 6)$.

Nevertheless, some evidences suggest roundabouts may reach saturation under moderate traffic volumes (7). Unbalanced flows among legs may not be a problem when the overall demand level is low. However, if one leg of a roundabout provides access to parking areas of shopping mall, the entry volumes of the corresponding approach will be high. This fact may increase delay on the next approaches, resulting in unnecessarily long queues and congestion (8).

Among possible solutions, such as changing roundabout design, implementing other form of intersection, or installing metering signals, the latter strategy is the most cost-effective measure (7). Metering signals regulate flow into circulating area of roundabouts from one approach and thereby creates larger gaps for downstream entries, alleviating thus, vehicle delays on roundabout legs (9). Full-time and partial-time metering strategies can be adopted. Roundabouts with full leg-by-leg control are not suitable for these cases since approaches must split in few seconds after signals are implemented (10). In turn, partial-metering can control a specific roundabout leg (9) during heavy demand periods and optimize delay for other legs.

Design guidelines available for transportation planners to implement metering signal systems at roundabouts are lacking. Applications of metered roundabouts have been mostly conducted in Australia, United Kingdom and in the United States (9).

One of the first studies in this topic was performed by Webb in 1994. He described the "SIG-NABOUT" that combined features of a signalized intersection and a roundabout (11). Typically, traffic lights are installed on roundabout approaches, but a second stop line to control left-turning traffic can be adopted (12). In this context, Fahmy (13) introduced an adaptive traffic signaling method based on fuzzy logic for roundabouts with four legs which recorded improvements in both waiting and moving times. Ma et al. (14) also proposed an optimization model to improve signal timings and design lane markings for signalized roundabout legs and circulating lanes. It was found that the optimal plan reduced construction costs and vehicle delay.

Akçelik (10) studied partial-metering roundabouts with one, two and three circulating lanes using the aaSIDRA model. The findings indicated that short cycle times (lower than those used in practice) improved delay, operation costs, fuel consumption and carbon dioxide $\left(\mathrm{CO}_{2}\right)$ emissions.

Hummer et al. (9) developed a macroscopic model based on the High Capacity Manual (HCM) formulas and validated it using VISSIM traffic model. Vehicle delays were computed for one cycle length under different signal locations in both single- and two-lane roundabouts. The proposed model neither was subjected to field testing nor included an emissions or noise criterion.

In a recent study on traffic operations and capacity at roundabouts by MartinGasulla et al. (7), the impacts of partial-metering strategies were conducted in two single- 
lane roundabouts in Spain. The authors suggested a reduction in average delay up to $60 \%$ depending on the combination of controlling traffic volumes and conflicting traffic flow.

Literature specifically about the use of partial-metering is scarce and mostly focused on achieving specific performance goals (9). Selection and design of partialstrategy may involve the balancing of other competing objectives, such as environmental, energetic and noise-related aspects.

With these concerns in mind, this study introduces a signal metering based-strategy with the main aim of reducing corridor-specific costs. These costs are represented by travel time, fuel consumption, global and local pollutant emissions, and traffic noise. The novelty of this paper is that it not only optimizes traffic performance measures but also environmental, energy and noise related-criteria on a link basis, which is crucial towards sustainable road transportation infrastructure.

This paper tests a signal partial-metering strategy at a real-world corridor near a shopping mall that often experiences congestion problems arising from heavy flow approaches. The objectives of this paper are threefold:

1. To evaluate corridor operations in terms of link-specific travel time, fuel use, $\mathrm{CO}_{2}$, nitrogen oxides $\left(\mathrm{NO}_{\mathrm{X}}\right)$, and noise costs;

2. To propose an optimization model to minimize above outputs;

3. To demonstrate model applicability under different traffic demand and directional split scenarios.

\section{METHODOLOGY}

The fundamental idea of the research methodology was to develop a modeling framework to optimize link costs with partial-metering (FIGURE 1). It involved the following tasks: i) to collect traffic, noise and vehicle dynamic data in one real-world corridor; $i$ ) to calibrate and validate traffic model; iii) to define a methodology to estimate costs; $i v$ ) to implement and optimize partial-metering signal according to link-specific costs; $v$ ) to compare optimal metered and unmetered (existing situation) solutions under variations in traffic demand and directional split distributions. 


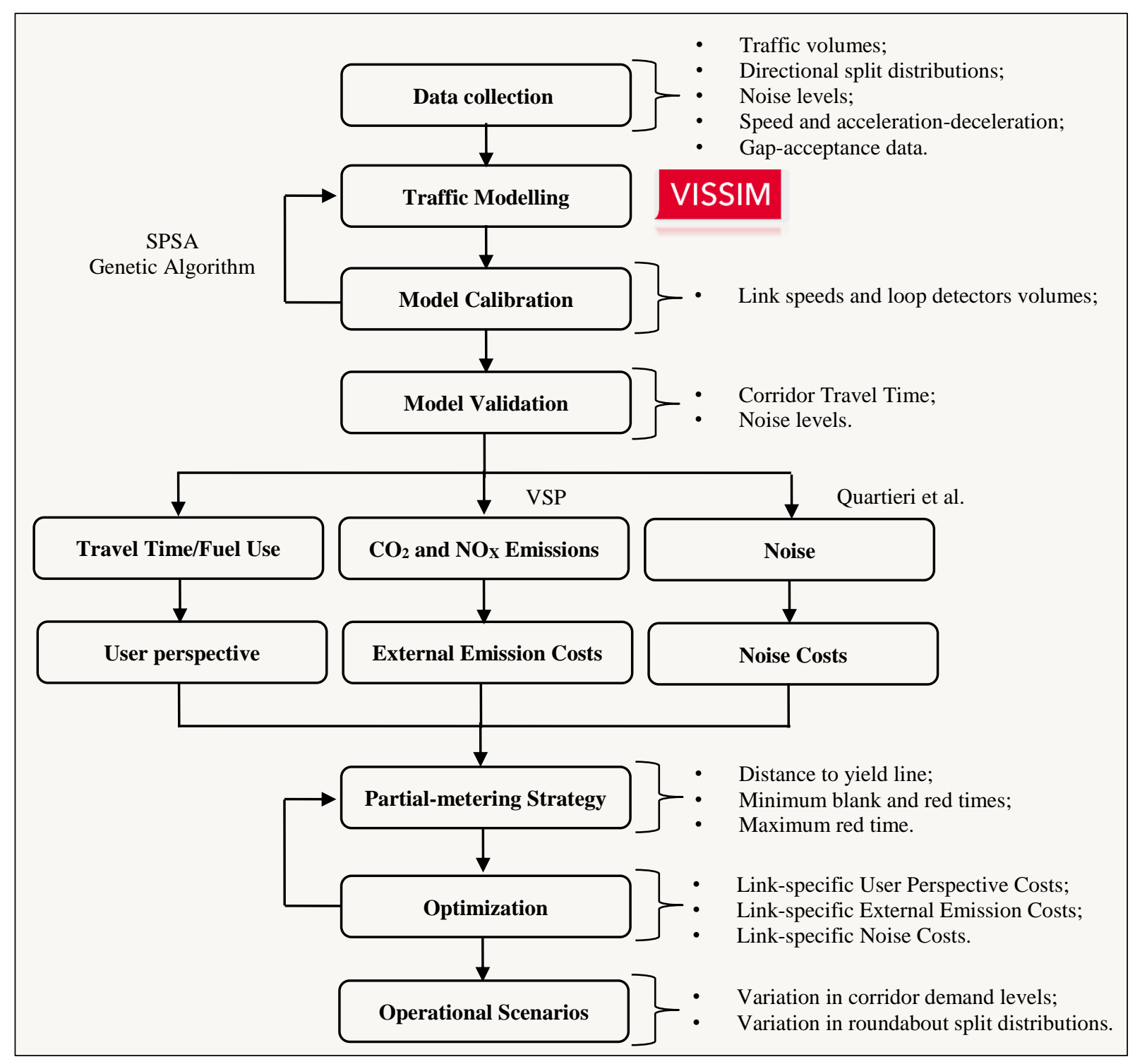

\section{FIGURE 1 Overview of the research methodology (SPSA - Simultaneous Perturbation Stochastic Approximation; VSP - Vehicle Specific Power).}

\subsection{Field Study}

Field measurements were conducted on a corridor near Guimarães (Portugal), which comprises a single-lane roundabout (RBT1), a signalized intersection (I1) and three twolane roundabouts (RBT2-RBT4) (FIGURE 2).

Corridor is a stretch along N206 national road ( 2.2km length) and is located near major industrial areas. It has one lane between RBT1 and RBT2 and two lanes on the other arterials and posted speed limits range from 40 (roundabout approaches) to $70 \mathrm{~km} / \mathrm{h}$. All roundabouts are suburban with small pedestrian impedance. I1 has a fixed-cycle with the same setup during the day (overall cycle time is 83s).

Depending on the day and demand period, the main stream is between RBT1 westbound and RBT4 southbound. RBT2 and RBT3 have unbalanced traffic flow among approaches and their Eastbound legs are distribution hubs. The Shopping Center nearby has 1,960 available parking lots and these roundabouts record high traffic volumes in some periods (especially on weekends and lunch/dinner periods). 


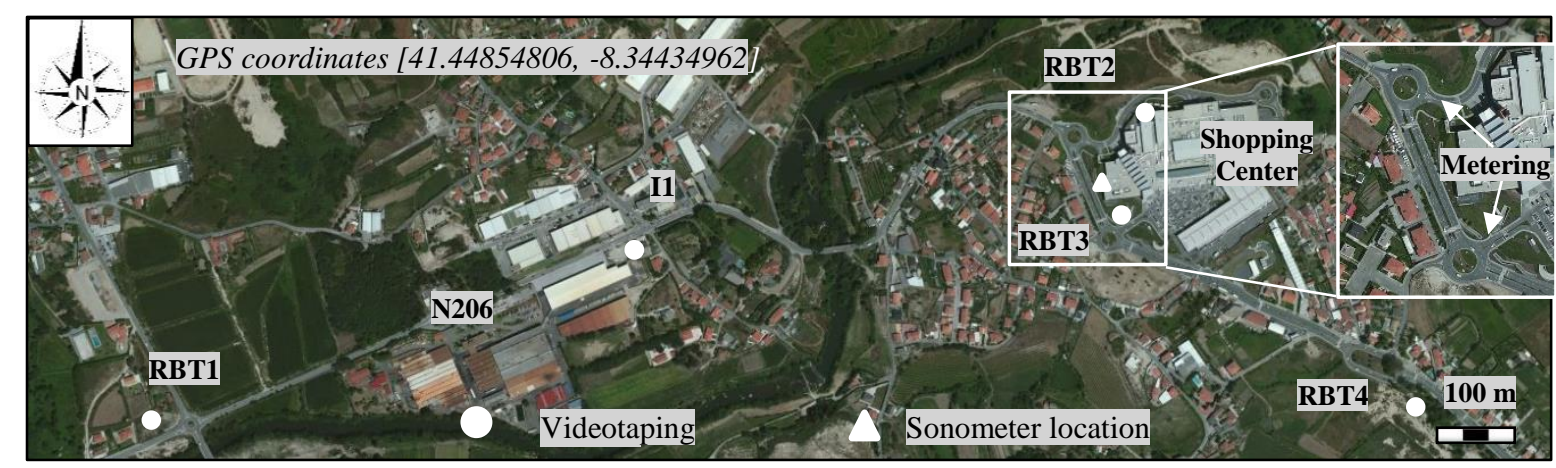

RBT1

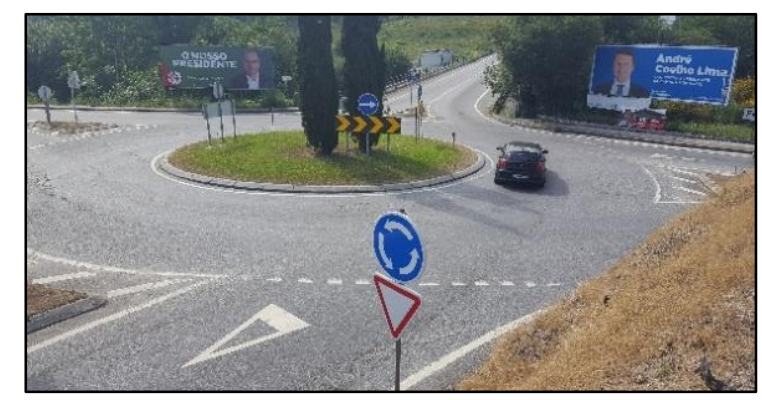

RBT3

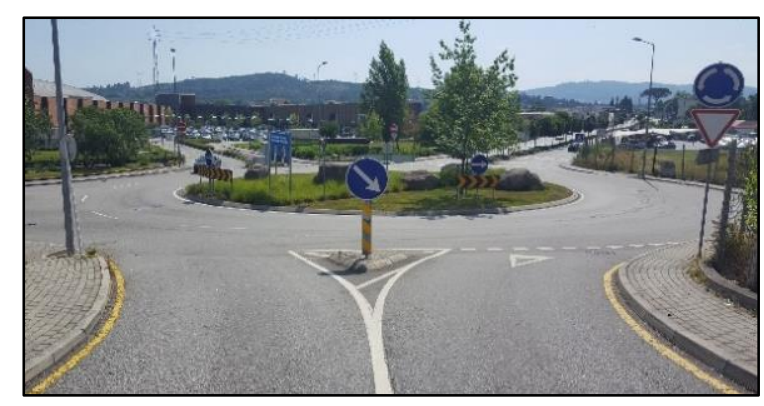

RBT2

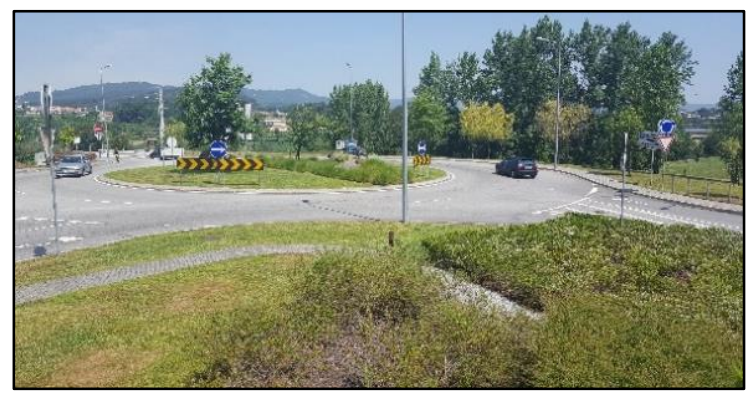

RBT4

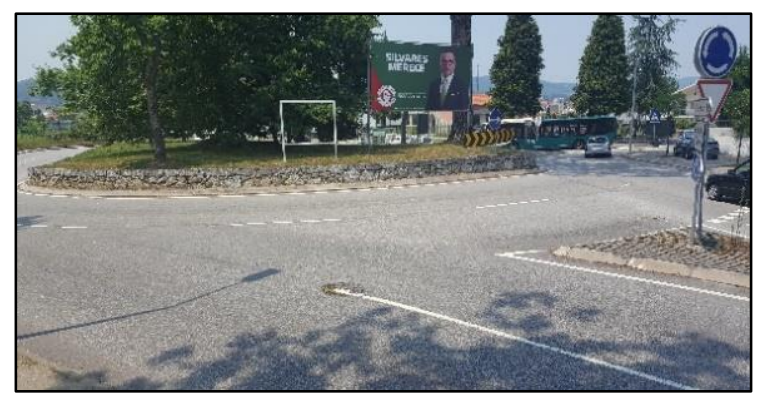

FIGURE 2 Aerial view of the studied corridor with suggested metering legs, equipment location and intersections identification [Source: Bing maps].

One set of traffic, vehicle dynamic and acoustic data was collected during a 12-h period (9:00AM-9:00PM) on a Sunday (which is the day with highest number of trips to the shopping mall) in June 2017 under dry weather conditions.

Cameras were installed at each intersection to gather intersection-specific direction split patterns. GPS devices were mounted on one passenger car to record vehicle dynamic data (second-by-second speed and acceleration-deceleration). About $100 \mathrm{~km}$ of data coverage (more than 40 GPS runs) for each through movement (RBT1-RBT4 and RBT4RBT1) were carried out for this research, according to a practice suggested in (15). Four different drivers (three males and one female, ages 27 to 35) performed these routes to ensure driving variability.

Noise data were collected using an integrating sound level meter RION-NL52 installed at locations near RBT2-RBT3 and followed the ISO 11819-1:1997 standard. Tests were conducted with wind speeds lower than $4 \mathrm{~km} / \mathrm{h}$ without the effects of other external sources, such as reflection and traffic from minor roundabout legs. The microphone was in the acoustic field at $1.2 \mathrm{~m}$ from the ground and at $15 \mathrm{~m}$ from the main road axis. The sound pressure levels were recorded every $1 \mathrm{~s}$. 


\subsection{Traffic, Emissions and Noise Modeling}

\subsubsection{Corridor Coding}

The studied corridor was implemented in VISSIM9 package tool (16). Link/connectors coding was made following good practices for signalized intersections and roundabouts (17). Their dimension was based on vehicle speed to guarantee enough space for vehicles stayed at least one time step in each link. This ensures that both noise and emission costs were not under estimated. Priority rules were introduced to reflect local driving habits on the roundabout approaches (18).

All simulation experiments assumed a 15-min "warm-up" prior analysis period to load the study domain (vehicles do not spend more than 10-min crossing the entire corridor).

\subsubsection{Emissions Assessment}

Emission estimates were based on VSP, a methodology providing instantaneous power per unit mass of vehicle taking into account aerodynamic drag, speed, acceleration, road grade and rolling distance effects (19). VSP values are categorized into 14 modes, and an emission factor for each mode was used to estimate the footprints of $\mathrm{CO}_{2}$ (impacted on global warming), and $\mathrm{NO}_{\mathrm{X}}$ (precursor to troposphere ambient ozone and with demonstrated effects in human health) emissions (19).

The team fit as much as possible the emission rates to the Portuguese car fleet, using 5 different vehicle types with the following composition (20): 39\% (1.4L 33\% + 1.8L 5.95\% + 2.2L 0.05\%) Light Duty Gasoline Vehicles, 40\% Light Duty Diesel Vehicles (1.9L), and 21\% Light Commercial Diesel Vehicles (2.5L). Their emission factors can be found elsewhere $(21 ; 22)$.

Despite significant differences may occur in total absolute emissions, the relative differences in emissions associated with above set of vehicles reflected vehicle dynamics patterns.

\subsubsection{Noise Assessment}

Quartieri et al. (23) methodology was used to calculate noise levels produced by road traffic. It includes speed data information which notably increases the precision of traffic noise estimates. Thus, source power level $\left(L_{w, i}\right)$ was first analyzed for all traffic flow in each link, and then overall corridor noise levels at a fixed distance were computed. Equation 1 gives the $L_{w, i}$ results for car passenger vehicles:

$$
\left\{\begin{array}{l}
82, \text { if } v<11.5 \mathrm{~km} \cdot \mathrm{h}^{-1} \\
\alpha+\beta \log v, \text { if } v>11.5 \mathrm{~km} \cdot \mathrm{h}^{-1}
\end{array},\right.
$$

where

$$
\begin{aligned}
& \alpha=53.6 \pm 0.3 \mathrm{dBA} ; \\
& \beta=26.8 \pm 0.2 \mathrm{dBA}(23) .
\end{aligned}
$$

Once the average link-speed data are obtained, the hourly equivalent noise level can be calculated using Equation 2 (24) :

$$
L_{e q, i}=10 \log N+\alpha+\beta \log v-20 \log d-47.563 \text {, }
$$

where:

$$
L_{e q, i}-\text { Link-specific equivalent noise level (dBA); }
$$


$N$ - Link-specific hourly traffic volume (vehicles per hour - vph);

$v$ - Link-specific average speed $\left(\mathrm{km} \cdot \mathrm{h}^{-1}\right)$;

$d$-Distance between the road axis and the receiver $(\mathrm{m})=7.5(23)$.

The methodology was validated by comparing measured and estimated noise data in different corridor locations (Section 3.2.2).

\subsubsection{Model Calibration and Validation}

The traffic model was calibrated and validated using different data sets (there was a random selection of $70 \%$ for calibration and $30 \%$ for validation). Three steps were performed, namely:

- Adjust driver behavior parameters [average standstill distance, additive and multiple parts of safety distance, time before diffusion, front and rear gaps, safety distance factor, and simulation resolution (16)] to assess their impacts on speeds by link (25), and traffic flows for each intersection entry and exit leg (loop detector);

- Use the SPSA Genetic Algorithm to optimize the adjusted parameters. Calibration stopped after Root Mean Squared Normalized Error (RMSNE) was lower than 15\% (26) at each point. RMSNE was computed using Equation 3:

$\operatorname{RMSNE}_{i}=\sqrt{\frac{1}{N} \sum_{j=1}^{N}\left(\frac{S V_{j}-O V_{j}}{O V_{j}}\right)^{2}}$,

where:

$N$ - Number of loop detectors in the coded network;

$S V_{j}$ - Simulated traffic volume in the loop detector $j\left(\mathrm{~km} \cdot \mathrm{h}^{-1}\right)$;

$O V_{j}$ - Observed traffic volume in the loop detector $j\left(\mathrm{~km} \cdot \mathrm{h}^{-1}\right)$.

- Validation compared corridor-specific simulated and observed travel time using the optimal calibration parameters with 10 random seed runs (25).

\subsection{Development of Link-based Costs}

\subsubsection{External Emission Costs}

The external emission cost approach focused on the quantification of the unequivocal impacts that emissions have on human health, environment, and economic activity.

The estimate damage $\mathrm{NO}_{\mathrm{X}}$ and $\mathrm{CO}_{2}$ costs per ton from transport is around $€ 1,957 /$ ton and $€ 90 /$ ton, respectively, for Portugal (27). Since exposure assessment is related to the population being exposed to air pollutant emissions, the local (parish level) population density is used to adjust average national costs suggested in literature for NOx. Specifically, it corresponds to the ratio between local (508.4 inhabittants. $\mathrm{km}^{-2}$ ) and national (114.5 inhabittants. $\mathrm{km}^{-2}$ ) (28) population densities. Thus, the integrated emission costs of a representative vehicle for each VSP mode was given by Equation 4:

$$
I E C_{i}=\sum_{j=1}^{5}\left(c_{1} \mu v_{j} \times e f_{\mathrm{NO}_{X}, j, i}+c_{2} v_{j} \times e f_{\mathrm{CO}_{2}, j, i}\right),
$$


where:

$I E C_{i}$ - Integrated emission costs for a representative vehicle and VSP mode ( $i=$ $1, \ldots, 14)\left(€ . \mathrm{s}^{-1}\right)$;

$c_{1}=1,957-$ National damage cost of $\mathrm{NO}_{\mathrm{X}}(€ /$ ton $)$;

$c_{2}=90-$ National damage cost of $\mathrm{CO}_{2}(€ /$ ton $)$;

$\mu=4.44$ - Ratio between local and national population density;

$v_{j}$-Share of the vehicle type $j$ in the vehicle park fleet;

ef $f_{j, i}-$ Emission factor for vehicle type $j$ for each VSP mode $i\left(\mathrm{~g} \cdot \mathrm{s}^{-1}\right)$.

It follows:

$I E C_{i}=\sum_{j=1}^{5} v_{j}\left(8,689 e f_{\mathrm{NO}_{X}, j, i}+90 e f_{\mathrm{CO}_{2}, j, i}\right)$,

Total external link-specific costs per kilometer (IEC) are obtained by summing $I E C_{i}$ for time spent in each VSP mode.

\subsubsection{Noise Costs}

Scarce information is available about noise-related costs from road traffic. Some methodologies do not account for speed effects, resulting thus, dispersed results in noise costs estimates. A naive approach was used in this paper to estimate noise costs (29). Average link noise cost was computed by multiplying the number of individuals in a noise range with the cost of noise in $€ / \mathrm{dBA}$ per exposed person and per hour for a range of noise divided by traffic in kilometers traveled (Equation 6):

$$
N C_{i}=\frac{\operatorname{Costs}\left(L_{i}\right)}{a \times b \times T} \times p o p,
$$

where:

$N C_{i}-$ Average link noise cost (€/dBA.veh.km)

Costs $\left(L_{i}\right)$ - Cost of a given noise level $L_{i}(€ /$ dBA per person and per year);

$a=365-$ Number of days;

$b=24-$ Number of hours;

pop - Number of person exposed to the noise level $L_{i}$;

$T$ - Traffic in vehicle kilometers (veh.km)

A value of 2,128 inhabitants (30) was used as reference of pop (local population) while monetary values to express Costs $\left(L_{j}\right)$ are presented in (29). It follows:

$$
N C_{i}=\frac{266}{1,095} \frac{\operatorname{Costs}\left(L_{i}\right)}{T},
$$

Lastly, total links costs $(N C)$ are obtained by summing $N C_{i}$ by each corridor link.

\subsubsection{User Perspective}

With respect to drivers' perspective, the impacts on travel time and fuel costs were estimated by using different criteria and sources to ponder the chosen parameters. A value of 3/4 of the ratio between local average wage and monthly hours showed suitable to provide an approximation of the average Value of Travel Time (VTT) for recreation trips 
(31). This study considered a $€ 713$ local average wage (32) and approximately $154 \mathrm{~h}$ monthly labor hours of (33), ending up with a VTT of $0.0009677 € . \mathrm{s}^{-1}$. The procedure for computing fuel-related costs is described by Equation 8 and includes fuel price, fuel consumption factor for each vehicle type associated with a VSP bin.

$$
I D C_{i}=0.0009677+\sum_{j=1}^{5} v_{j} \times F C_{j, i} \times P_{j},
$$

where:

$I D C_{V S P i}-$ Integrated Driver Costs by VSP mode $(i=1, \ldots, 14)\left(€ . \mathrm{s}^{-1}\right)$;

$v_{j}$-Share of the vehicle type $i$ in the vehicle park fleet;

$F C_{j, i}-$ Fuel consumption factor for vehicle type $j\left(\mathrm{~L} . \mathrm{s}^{-1}\right)$;

$P_{j}$ - Price of Fuel (Diesel or Gasoline) for vehicle type $j\left(€ . \mathrm{L}^{-1}\right)$.

Total link-specific costs as user perspective per kilometer (IDC) are computed by summing $I D C_{i}$ for time spent in each VSP mode.

\subsection{Operational Scenarios}

To measure the merits of partial-metering strategy, two main demand scenarios for both baseline (unmetered) and metered cases were defined:

1) Different traffic volumes at the RBT2 and RBT3 East entries, assuming no changes in the directional splits at all intersections and traffic volumes on the other RBT2-RBT3 legs;

2) Different left-turning rates at the RBT2 and RBT3 East entries, assuming no changes in the total entry flow and directional splits distributions on the other intersections.

The effects of both the uniform traffic growth and directional split distributions were evaluated at three levels each: traffic growth consisting of demand factors of $100 \%$ (observed), $150 \%$ and $200 \%$; and left-turning rates of $60 \%, 70 \%$ and $80 \%$. It is worth noting that the highest traffic growth scenario had a lower demand than the available shopping parking capacity.

\subsection{Metered Strategy and Optimization}

\subsubsection{Partial-Metering System}

An indirect (not controlled circulating traffic with priority) and part-control (one roundabout approach was under control) metering system was used. RBT2 and RBT3 East approaches were the candidates for the implementation of this system.

Conceptually, if signal is red, approaching vehicles will stop before the signal head. If it is blank/amber, vehicles will drive normally and will enter the roundabout when an appropriate gap emerges. During blank signal, the light will be off so that it will not mislead the entering traffic. The minimum blank and red times should be enough to have a trustworthy system for drivers when leaving the shopping mall, while maximum red time must avoid excessive delays on the controlling approaches.

Once partial-metering system was implemented in VISSIM (16), the following design parameters and corresponding reference values (7) were defined: $a$ ) distance to yield line - 14-24m; $b$ ) minimum blank time setting - 20-50s; $c$ ) minimum red time setting $-10-20 \mathrm{~s}$; and $d$ ) maximum red time setting $-30-80$ s. 
Since the traffic flow at the candidate approaches was stationary over short periods (1-h), fixed-time signal timing was used. To simplify the optimization, the distance to yield line and maximum red time setting were set at $15 \mathrm{~m}$ and 30 s, respectively, for all operational scenarios (7). Also, the time settings were assumed to be equal in both metered approaches.

\subsubsection{Optimization Formulation}

The implementation of the partial-metered signals results in a trade-off. On one hand, the control delay on metered approaches is higher than that observed in baseline conditions. On the other hand, some links may record less costs because vehicles in the adjacent approaches may have more gaps in the circulating stream.

The main goal of the proposed multiobjective model was to minimize the overall costs based on Equations (5), (7) and (8), considering times blank ( $\left.t_{\text {blank }}\right)$ and red $\left(t_{\text {red }}\right)$ as decision variables bounded as follows:

$$
\begin{aligned}
& 20 \leq t_{\text {blank }} \leq 50 \\
& 10 \leq t_{\text {red }} \leq 30
\end{aligned}
$$

Additionally, the candidate metered approaches have to yield medium-low volumeto-capacity ratios (v/c $<0.7)$ to maintain tolerable operating conditions $(7)$ when partialmetering signals are introduced. Combining the objective functions and main constraints, the optimization problem can be formulated as follows (Equation 11):

$$
\begin{aligned}
& \min f(I E C, N C, I D C)=\left(f\left(\operatorname{IEC}\left(t_{\text {blank }}, t_{\text {red }}\right)\right), f\left(N C\left(t_{\text {blank }}, t_{\text {red }}\right)\right), f\left(\operatorname{IDC}\left(t_{\text {blank }}, t_{\text {red }}\right)\right)\right) \\
& 20 \leq t_{\text {blank }} \leq 50 \\
& \text { subject to } \begin{array}{l}
10 \leq t_{\text {red }} \leq 30 \\
\mathrm{v} / \mathrm{c}_{\mathrm{RBT} 2}<0.7 \\
\mathrm{v} / \mathrm{c}_{\mathrm{RBT3}}<0.7
\end{array}
\end{aligned}
$$

Objective functions were constructed using multiple linear regressions, whose coefficients were obtained taking into account several simulations in 5-s increments for the decision variables, for each scenario. A total of 35 combinations of control metering signals parameters were performed to obtain optimal settings (total of 2,100 simulations in VISSIM).

\subsubsection{Optimization Algorithm}

The above partial-metered signal multiobjective optimization can search the optimal timing scheme, expressed as $t_{\text {blank }}$ and $t_{\text {red. }}$. Equation 11 is a bound constrained multiobjective optimization problem that was solved by using an SQP-type approach (34). The algorithm performs sequential quadratic programming-type iterations to build an approximation to the Pareto front. Numerical results in the form of performance and data profiles show that it outperforms the Non-dominated Sorting Genetic Algorithm (NSGA), for a considerable number of benchmark problems (34).

The main difference to other algorithms is that this new algorithm updates a finite set of points at each iteration, instead of a single one. The procedure is divided into three stages: 1) initialization; 2) spread; and 3) optimality-refining (34). In the initialization stage, initial guesses for Pareto points are provided. Then, in the spread stage, a set of new 
points, enriched with nondominated points, is computed such that the set of their images is spread along the Pareto front. Finally, a refining process is applied to construct a sequence of converging points. During the procedure, derivatives of objective functions are assumed to be available, quadratic approximations to the objectives are considered and various auxiliary optimization subproblems have to be solved.

The team adapted the Multiobjective Sequential Quadratic Programming solver, which is a publicly available MATLAB implementation of the algorithm (34).

\section{RESULTS AND DISCUSSION}

\subsection{Field Measurements}

The analysis of corridor-specific demand patterns showed that the period with highest traffic volumes occurred between 5:30-6:30PM. Thus, such period was selected for the implementation of partial-metering strategy.

TABLE 1 lists observed values of traffic volumes on each approach, the Level-ofService (LOS) criteria and v/c (35). The number of vehicles entering each intersection ranged from 1,305 to 2,360 vph for I1 and RBT4, respectively, and 1\% of traffic volume was composed of Heavy-Duty Vehicles (HDV). The findings showed that roundabout's approaches mostly operated with control delays lower than 10s (35). As suspected, RBT2 and RBT3 East approaches induced slight delays on the North approaches (LOS B). This happened because approximately 50\% of RBT2 and RBT3 traffic from East approaches went left. Despite all intersections had v/c of 0.85 or less, I1 main approaches operated with an unstable flow (LOS D) (35).

TABLE 1 Traffic performance results between 5:30-6:30PM

\begin{tabular}{|c|c|c|c|c|c|c|c|c|c|c|c|c|}
\hline \multirow[b]{2}{*}{ ID } & \multicolumn{3}{|c|}{ North Approach } & \multicolumn{3}{|c|}{ South Approach } & \multicolumn{3}{|c|}{ West Approach } & \multicolumn{3}{|c|}{ East Approach } \\
\hline & $\begin{array}{c}\text { Entry } \\
\text { Volume } \\
\text { [vph] }\end{array}$ & $\begin{array}{l}\text { L } \\
\mathbf{O} \\
\text { S }\end{array}$ & $\mathbf{v} / \mathbf{c}$ & $\begin{array}{c}\text { Entry } \\
\text { Volume } \\
\text { [vph] }\end{array}$ & $\begin{array}{l}\mathbf{L} \\
\mathbf{O} \\
\mathbf{S} \\
\end{array}$ & $\mathbf{v} / \mathbf{c}$ & $\begin{array}{c}\text { Entry } \\
\text { Volume } \\
\text { [vph] } \\
\end{array}$ & $\begin{array}{l}\text { L } \\
\mathbf{O} \\
\text { S }\end{array}$ & $\mathbf{v} / \mathbf{c}$ & $\begin{array}{c}\text { Entry } \\
\text { Volume } \\
\text { [vph] } \\
\end{array}$ & $\begin{array}{l}\mathbf{L} \\
\mathbf{O} \\
\mathbf{S} \\
\end{array}$ & $\mathbf{v} / \mathbf{c}$ \\
\hline RBT1 & 446 & A & 0.41 & 302 & A & 0.30 & 520 & A & 0.46 & 509 & A & 0.38 \\
\hline I1 & 81 & E & 0.48 & 6 & $\mathrm{D}$ & 0.25 & 676 & E & 0.82 & 532 & $\mathrm{D}$ & 0.77 \\
\hline RBT2 & 744 & B & 0.72 & 404 & A & 0.27 & & $/ A$ & & 307 & A & 0.26 \\
\hline RBT3 & 792 & B & 0.48 & 835 & A & 0.28 & 24 & A & 0.06 & 374 & A & 0.40 \\
\hline RBT4 & 1,096 & A & 0.41 & 871 & $\mathrm{~A}$ & 0.37 & & $/ A$ & & 389 & $\mathrm{C}$ & 0.37 \\
\hline
\end{tabular}

Note - N/A: Not Applicable

\subsection{Calibration and Validation}

\subsubsection{Traffic Model}

FIGURE 3 exhibits observed and estimated vehicle speeds (147 links) and traffic volumes (34 loop detectors) after calibration of the traffic model. The results confirmed good fit between simulated and observed data using a linear regression. The predicted $R^{2}$ was 0.94 and 0.98 for simulated seeds and traffic volumes, respectively. Also, the calibration target was reached since RMSNE was only $4 \%$ (26).

The comparison of observed and simulated travel time was performed using 30 floating car runs (15). The average travel time differences were, respectively, $7 \%$ ( $p$-value $=0.29>0.05$, and thus, not statistically significant) and $6 \%$ ( $p$-value $=0.07$, also not statistically significant) in the directions RBT1-RBT4 (observed - 209s; simulated - 233s) 
and RBT4-RBT1 (observed - 208s; simulated - 220s). The calibrated parameters in the bottom of FIGURE 3 were then applied to the subsequent scenarios.

a)

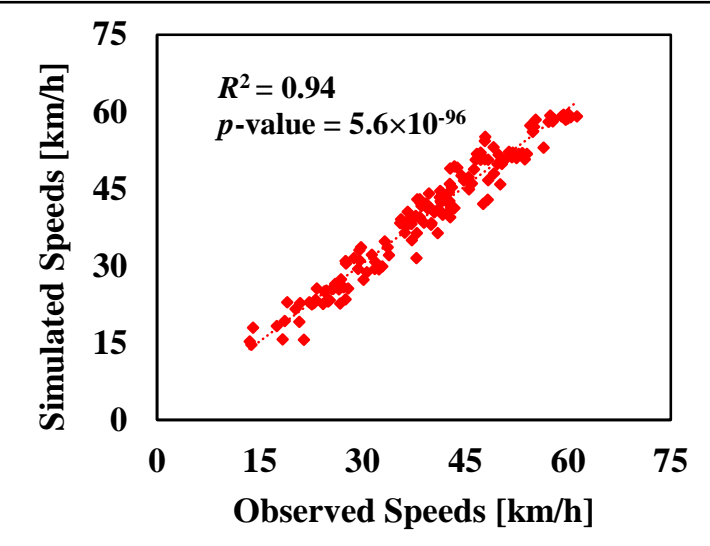

b)

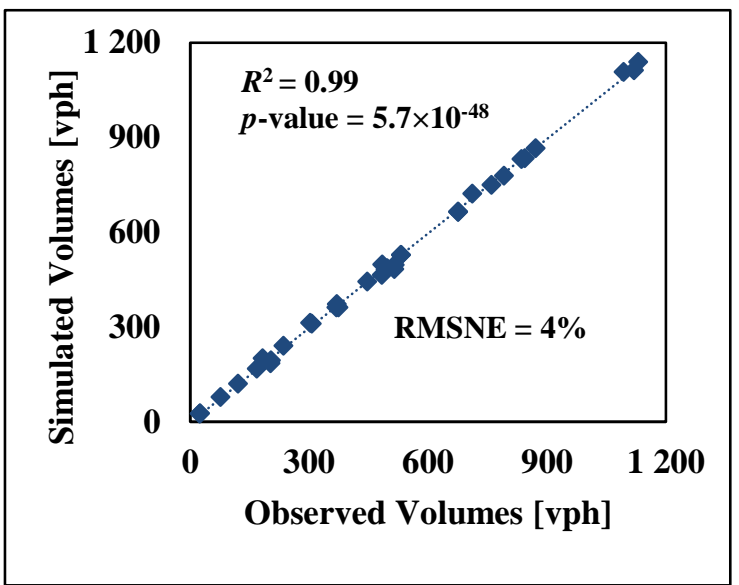

Note - p-value is F-test (ANOVA) performed in $R^{2}$ coefficients.

Calibrated Model Parameters - Average standstill distance: $0.5 \mathrm{~m}$; Additive part of safety distance: 0.95; Multiple part of safety distance: 1.15; Time before diffusion: 120 s; Front Gap: 0.35 s; Rear Gap: 0.35 s; Safety Distance Factor: 1.15; Simulation Resolution: time steps per simulation seconds.

\section{FIGURE 3 Calibration of traffic model: a) speeds; b) traffic volumes.}

\subsection{2. $\quad$ Noise Model}

This section analyzed the capability of the noise methodology to estimate site-specific noise. Seven data sets of 15-min ( $L_{\mathrm{eq}}$ and respective arterial traffic in front of sound meter) were selected in different corridor locations to ensure variability in the comparison (FIGURE 4). The estimated noise approach from Quartieri et al. (24) fit the field data (differences ranged from $1 \%$ to 5\%). The highest differences between estimated and observed noise ( $\sim 3 \mathrm{dBA})$ may be due to the presence of HDV that were not included in the $L_{e q}$ formula. The decrease in experimental noise in high-volume values $(1,300$ and 1,500 vph) was explained by traffic congestion (lower speeds).

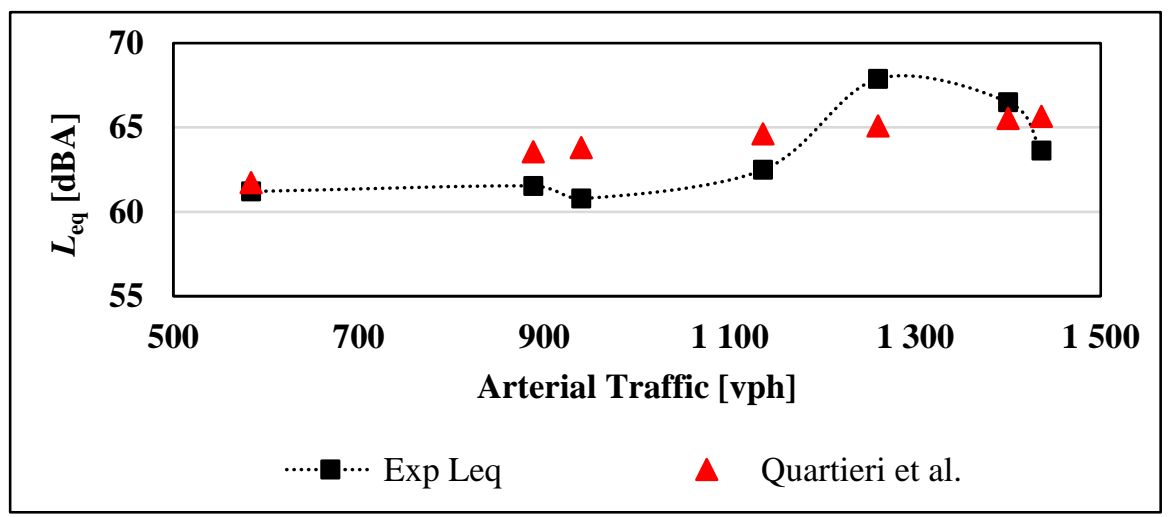

FIGURE 4 Validation of traffic noise methodology. 


\subsection{Comparison between Baseline and Optimal Metered Conditions}

The main results of the multiobjective optimization of partial-metered system with observed traffic demand $(100 \%)$ is presented in this section. The following optimal signal timing settings were obtained for both signals at RBT2 and RBT3 East approaches:

- $\quad t_{\text {blank }}=26 \mathrm{~s} ; t_{\text {red }}=10 \mathrm{~s}(\mathrm{v} / \mathrm{c}<0.7)$;

Under the optimal model, IEC, NC and IDC costs decreased by $6 \%, 13 \%$ and $2 \%$, respectively, compared to the baseline (unmetered). The implementation of metered solution allowed $I E C$ and $I D C$ costs to be reduced by more than $10 \%$ on links upstream RBT2 and RBT3 (North direction). In contrast, overall costs at metered approaches increased by $50 \%$.

FIGURE 5 a-c depicted the hotspot costs location on the shopping mall accesses with baseline scenario. Analysis results showed links with highest IEC were found at the upstream, downstream and circulating areas of RBT2, RBT3 and RBT4. This was $60 \%$ more than the average $I E C$ corridor value $\left(13 € . \mathrm{km}^{-1}\right) . N C$ had a similar distribution near shopping mall (FIGURE 5-b) but high values ( $>10 € /$ dBA.veh.km) were observed in RBT3 West approach. This happened because these links had short length $(<10 \mathrm{~m})$ and low traffic volumes. The findings from IDC showed an identical trend, as IEC did (FIGURE 5-c). Fuel consumption and travel time related costs along the downstream and upstream were higher $70 \%$ than the average corridor value.

When looking at link-specific range values with partial-metered strategy (FIGURE $5 \mathrm{~d}-\mathrm{f})$, both RBT2 and RBT3 North approaches were notably improved. Specifically, IEC and $I D C$ had yellow or green colors while in unmetered case these were orange or red (highest range of values). Other benefit was observed at mid-block section between RBT2 and RBT3. This point was explained by low stop-and-go situations in North approach of RBT3 (vehicles were not retained by exiting shopping parking traffic) which in turn benefited RBT2 operations. 
a)

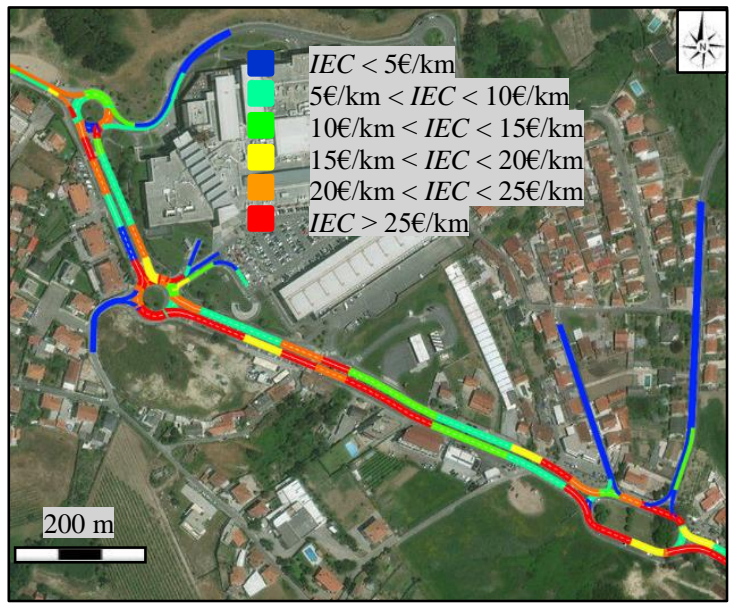

b)

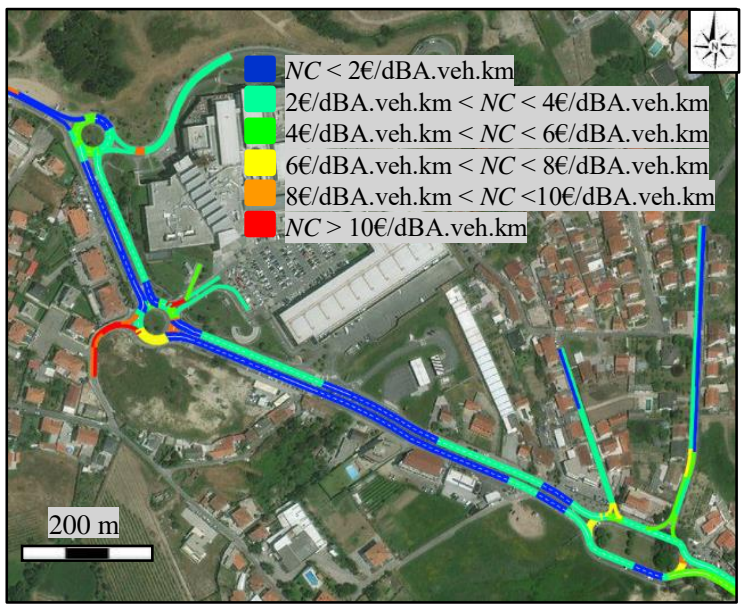

c)

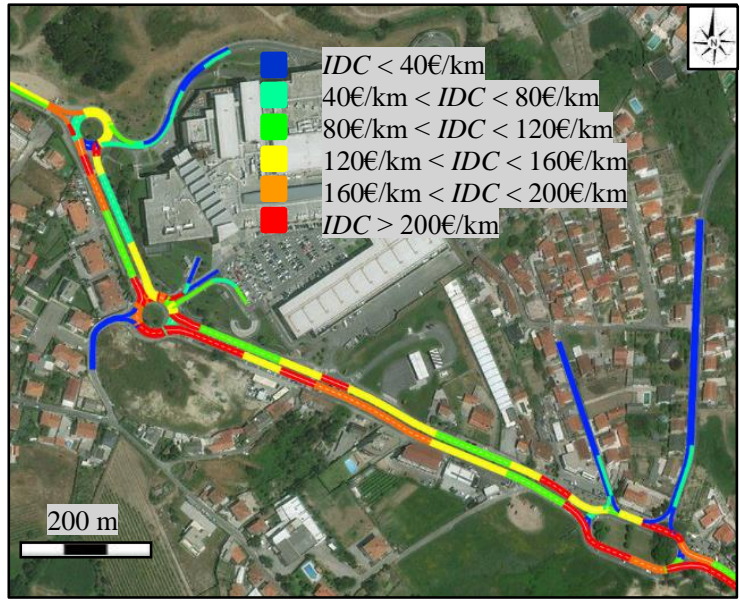

d)

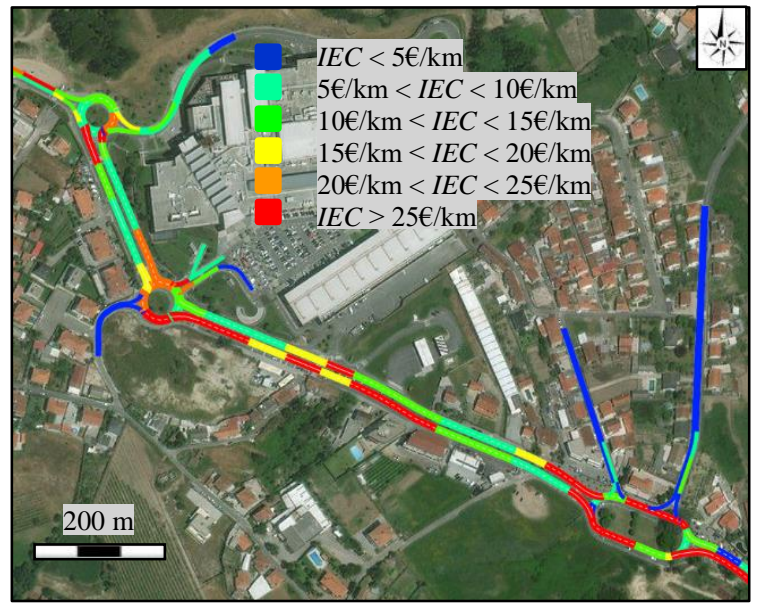

c)

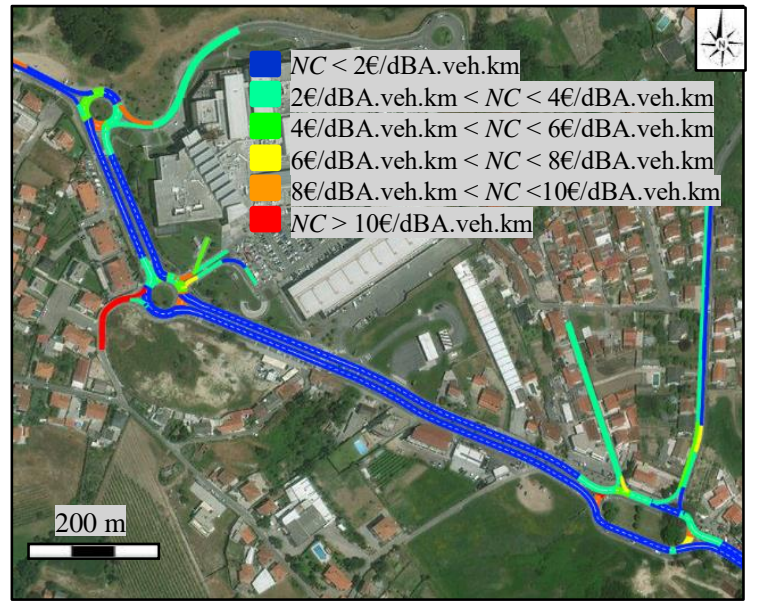

f)

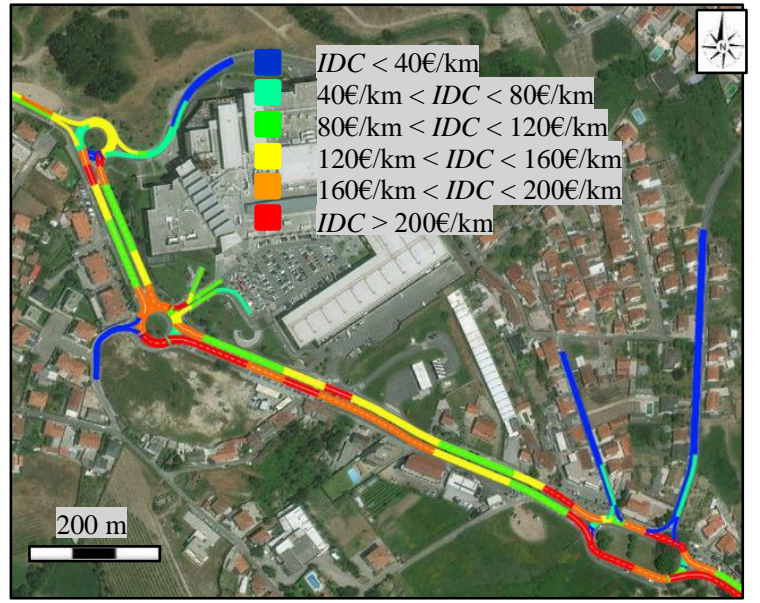

FIGURE 5 Overview link costs near shopping mall: a) IEC - Baseline; b) $\mathrm{NC}$ Baseline; c) $I D C$ - Baseline; d) IEC-Metered; e) $N C$ - Metered; f) $I D C$ - Metered (Source: Bing Maps). 


\subsection{Sensitivity Analysis}

To quantify the benefit at different operational scenarios, a comparison between partialmetered system and baseline was conducted. The optimization model best solutions by each scenario were the following:

- $150 \%-t_{\text {blank }}=20 \mathrm{~s} ; t_{\text {red }}=10 \mathrm{~s}$;

- $200 \%-t_{\text {blank }}=46 \mathrm{~s} ; t_{\text {red }}=28 \mathrm{~s}$;

- $60 \% \_$Left $-t_{\text {blank }}=50 \mathrm{~s} ; t_{\text {red }}=10 \mathrm{~s}$;

- $70 \% \_$Left $-t_{\text {blank }}=50 \mathrm{~s} ; t_{\text {red }}=10 \mathrm{~s}$;

- $80 \% \_$Left $-t_{\text {blank }}=45 \mathrm{~s} ; t_{\text {red }}=26 \mathrm{~s}$.

These values are in accordance with previous studies in partial-metered strategy conducted in roundabouts (7). Almost all scenarios yielded optimal signal timing settings with long $t_{\text {blank }}$ and short $t_{\text {red. }}$. For the $200 \%$ traffic growth scenario, however, an optimal $t_{\text {red }}$ of 28s was suggested. This occurred because East approach traffic reached a demand so that the adjacent legs (RBT2 and RBT3 North approaches) were not able to discharge their queues with unmetered conditions. Even though metered approaches have been poorly performed with long red times, it seems this setting brings benefits to the overall corridor.

FIGURE 6 a-c exhibited $I E C, N C$ and $I D C$ costs for both unmetered and metered systems for each testing scenario. Some conclusions were:

- Metered signals improved corridor operations regardless of traffic growth scenarios $(100 \%, 150 \%$ and $200 \%)$. For the $150 \%$ growth scenario, benefits could up to $10 \%$ for all costs;

- Partial-metered system became more effective in reducing costs when entering demands at RBT2 and RBT3 East approaches increased. It had average external costs (IEC and NC) of about 6\%, while user perspective costs decreased by more than $7 \%$;

- The differences in both $I D C$ and $I E C$ costs between solutions were found to be small $(<2 \%)$ with different left-turning rates at the RBT2 and RBT3;

- Partial-metered system offered benefit in reducing $N C$ under very high leftturning rates. It yielded $6 \%$ lower noise-related costs compared with those obtained without metered. 
a)

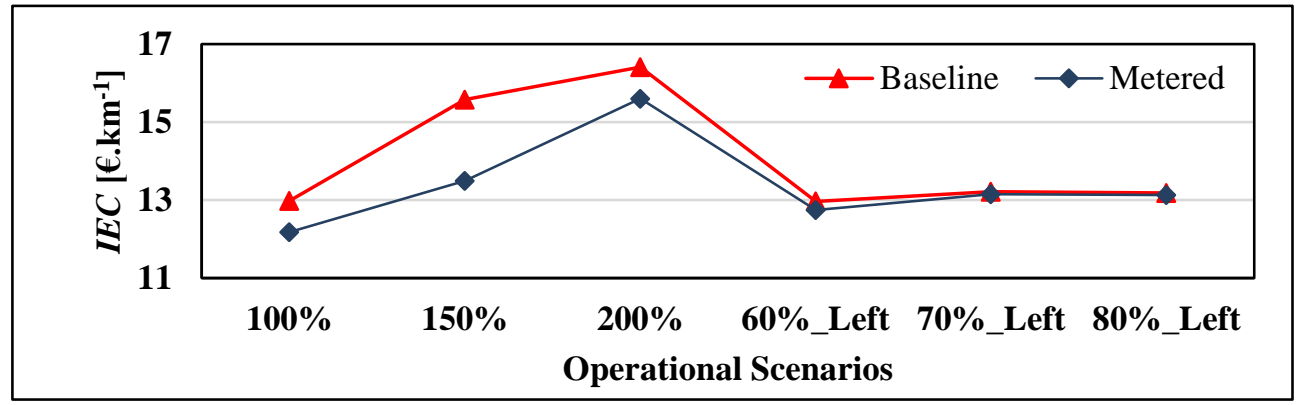

b)

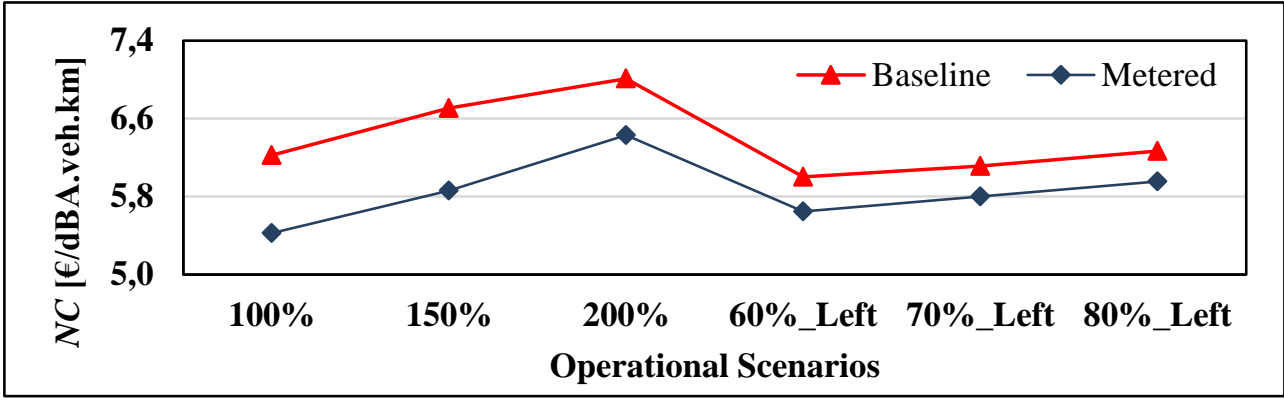

c)

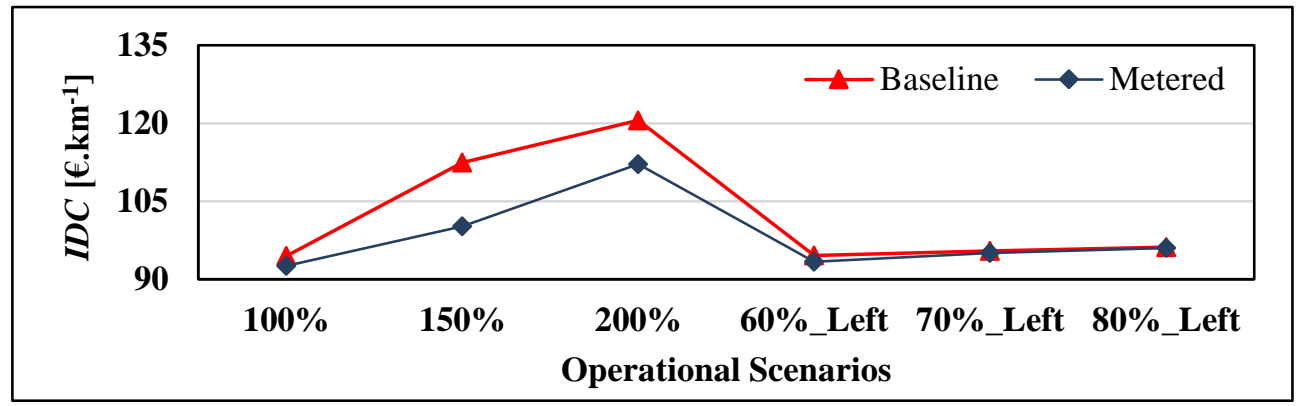

FIGURE 6 Link costs under different operational scenarios: a) IEC; b) $N C$; c) IDC.

\section{CONCLUSIONS}

This paper explored the benefits of implementing a partial-metering strategy on roundabout legs with access to shopping mall parking. The system was designed to minimize link-specific external damage, noise and user damage costs. The study also examined the system applicability under several combinations of traffic demand and leftturning rates.

A corridor with roundabouts and a signalized intersection in Portugal was characterized. Site-specific operations were calibrated and validated in VISSIM model. Then, different combinations of blank and red times were tested and their impacts on overall costs quantified. As a solution for proposed problem, an SQP-type approach searched for optimal timing settings.

It was concluded that, under existing traffic demand, overall costs decreased up to $13 \%$ compared to the unmetered condition. The adoption of short red times (10s) and long blank times (50s) had a better impact on the controlling approach in almost scenarios. The findings suggested that partial-metered system was effective when entering demands at the 
metered approaches increased. In such cases, external and internal damage costs reduced approximately $6 \%$ and $7 \%$, respectively.

This study contributes to determine the need of a metered-based strategy at roundabouts near a shopping mall, and its expected benefits in improving a wide range of parameters besides traditional traffic performance measures. This included environmental, energetic or traffic noise criteria, which are essential towards a better economy in future road transportation. The proposed system can be straightforwardly used by practitioners as well as be adapted by research community to include other transportation-related externalities.

Although the utility of metering system on the candidate corridor has been demonstrated, there are some limitations that must be outlined: 1) findings were based on a simulation environmental with identical gap acceptance and car-following behaviors; 2) partial-system operated with fixed-controlled settings; 3) signal optimization only accounted for timing; 4) pedestrian or cyclist impedance effects were discarded. Therefore, it would be interesting, as future work:

- To study sites where heavy-duty, pedestrian and cyclist volumes are high;

- To develop a link-specific indicator to express safety-related costs;

- To implement a control logic system on the microsimulation platform based on location and timing;

- To conduct a sensitivity analysis of corridor traffic volumes and conflicting traffic flows (in relation to the metered approaches) for which the metered system becomes inefficient.

\section{ACKNOWLEDGEMENTS}

The authors acknowledge to the projects: PTDC/EMS-TRA/0383/2014, that was funded within the project 9471-Reiforcement of RIDTI and funded by FEDER funds; Strategic Project UID-EMS-00481-2013-FCT and CENTRO-01-0145-FEDER-022083; CISMOB Project (PGI01611, funded by Interreg Europe Programme); MobiWise project: From mobile sensing to mobility advising (P2020 SAICTPAC/0011/2015), co-financed by COMPETE 2020, Portugal 2020 - Operational Program for Competitiveness and Internationalization (POCI), European Union's ERDF (European Regional Development Fund), and the FCT. Finally, the cooperation of Toyota Caetano Auto is appreciated which allowed the use of vehicles for data collection.

\section{REFERENCES}

[1] Rodegerdts, L., et al. Roundabouts: An Informational Guide - Second Edition. Publication NCHRP 672, Transportation Research Board, Washington, DC, 2010.

[2] Alluri, P., A. Gan, A. Diaz, and R. Steiner. Safety Impacts of Access Management Features near Roundabouts. Transportation Research Record: Journal of the Transportation Research Board, Vol. 2517, 2015, pp. 28-36.

[3] Bugg, Z., B. Schroeder, P. Jenior, M. Brewer, and L. Rodegerdts. A Methodology to Compute Roundabout Corridor Travel Time. Presented at 94th Annual Meeting of the Transportation Research Board, Washington, DC, 2015.

[4] Isebrands, H., S. Hallmark, E. Fitzsimmons, and J. Stroda. Toolbox to Evaluate the Impacts of Roundabouts on a Corridor or Roadway Network. Publication K-TRAN: KSU09-10, Kansas State University Transportation Center, 2008. 
[5] Ariniello, A. Are Roundabouts Good for Business?

www.cityofgolden.net/media/roundaboutpaper.pdf, Accessed May 18, 2017.

[6] Russell, E., E. Landman, and R. Godavarthy. A Study of the Impact of Roundabouts on Traffic Flows and Business. Publication K-TRAN: KSU-09-10, Kansas State University Transportation Center, 2012.

[7] Marilo, G., G. Alfredo, and A. Moreno. Benefit Measurement of metering signals at roundabouts with 4 unbalanced-flow patterns in Spain. Presented at 95th Annual Meeting of the Transportation Research Board, Washington, DC, 2016.

[8] Valdez, M., R. Cheu, and C. Duran. Operations of Modern Roundabout with Unbalanced Approach Volumes. Transportation Research Record: Journal of the Transportation Research Board, Vol. 2265, 2011, pp. 234-243.

[9] Hummer, J., J. Milazzo, B. Schroeder, and K. Salamati. Potential for Metering to Help Roundabouts Manage Peak Period Demands in the United States. Transportation Research Record: Journal of the Transportation Research Board, Vol. 2402, 2014, pp. 56-66.

[10] Akçelik, R. Roundabout Metering Signals: Capacity, Performance and Timing. Procedia - Social and Behavioral Sciences, Vol. 16, 2011, pp. 686-696.

[11] Webb, P. J. "SIG-NABOUT"-the development and trial of a novel junction design. Seventh International Conference on Road Traffic Monitoring and Control, 1994. pp. 106110.

[12] Xiaoguang, Y., L. Xiugang, and X. Kun. A new traffic-signal control for modern roundabouts: method and application. IEEE Transactions on Intelligent Transportation Systems, Vol. 5, No. 4, 2004, pp. 282-287.

[13] Fahmy, M. An Adaptive Traffic Signaling For Roundabout With Four Approach Intersections Based On Fuzzy Logic. Journal of computing and information technology, Vol. 15, No. 1, 2007, pp. 33-45.

[14] Ma, W., Y. Liu, L. Head, and X. Yang. Integrated optimization of lane markings and timings for signalized roundabouts. Transportation Research Part C: Emerging Technologies, Vol. 36, 2013, pp. 307-323.

[15] Fries, R., Y. Qi, and S. Leight. How many times should I run the Model? Performance Measure. Specific Findings from VISSIM models in Missouri. Presented at 96th Annual Meeting of the Transportation Research Board, Washington, DC, 2017.

[16] PTV AG. PTV VISSIM 9 User Manual. Planung Transport Verkehr AG, Karlsruhe, Germany, 2016.

[17] Fontes, T., S. R. Pereira, P. Fernandes, J. M. Bandeira, and M. C. Coelho. How to combine different microsimulation tools to assess the environmental impacts of road traffic? Lessons and directions. Transportation Research Part D: Transport and Environment, Vol. 34, 2015, pp. 293-306.

[18] Vasconcelos, A., A.M. Seco, and A.B. Silva. Comparison of procedures to estimate critical headways at roundabouts. Promet-Traffic\&Transportation, Vol. 25, No. 1, 2013, pp. 43-53.

[19] US EPA. Methodology for developing modal emission rates for EPA's multi-scale motor vehicle \& equipment emission system. Publication Prepared by North Carolina State University for US Environmental Protection Agency, EPA420, Ann Arbor, MI, 2002.

[20] EMISIA. COPERT Countries data. http://emisia.com/products/copert-data. Accessed May 16, 2017.

[21] Anya, A. R., N. M. Rouphail, H. C. Frey, and B. Liu. Method and Case Study for Quantifying Local Emissions Impacts of Transportation Improvement Project Involving 
Road Realignment and Conversion to Multilane Roundabout. Presented at 92nd Annual Meeting, Transportation Research Board, Washington, DC, 2013.

[22] Coelho, M. C., H. C. Frey, N. M. Rouphail, H. Zhai, and L. Pelkmans. Assessing methods for comparing emissions from gasoline and diesel light-duty vehicles based on microscale measurements. Transportation Research Part D: Transport and Environment, Vol. 14, No. 2, 2009, pp. 91-99.

[23] Quartieri, J., G. Iannone, and C. Guarnaccia. On the Improvement of Statistical Traffic Noise Prediction Tools. 11th WSEAS Int. Conf. on Acoustics \& Music: Theory \& Applications, Iasi, Romania, June 13-15, 2010. pp. 201-207.

[24] Guarnaccia C. Advanced Tools for Traffic Noise Modelling and Prediction. WSEAS Transactions on Systems, Vol. 12, 2013, pp. 121-130.

[25] Winnie, D., B. Christine, and H. Serge P. Traffic Simulation and Data: Validation Methods and Applications. CRC Press, Taylor \& Francis Group, Boca Raton, FL, 2014.

[26] FDOT. Traffic Analysis Handbook: Reference for Planning and Operations. Florida Department of Transportation, Tallahassee, FL, 2014.

[27] Artem, K., D. Nicola, B. Johannes, H. Michael, M. Henning, G. Gena, V. Adarsh, and C. Victoria. Update of the Handbook on External Costs of Transport - Final Report. Publication Prepared by DG Mobility and Transport for the European Commission, MOVE/D3/2011/571, London, United Kingdom, 2014.

[28] Statistics of Portugal. Population's density by Place of residence. https://ine.pt. Accessed July 12, 2017.

[29] Le Maitre, H. Noise Costs for Road Traffic. Presented at 94th Annual Meeting of the Transportation Research Board, Washington, DC, 2015.

[30] Statistics of Portugal. Resident persons (No.) in family nuclei by Place of residence. https://ine.pt. Accessed July 12, 2017.

[31] Fezzi, C., I. J. Bateman, and S. Ferrini. Using revealed preferences to estimate the Value of Travel Time to recreation sites. Journal of Environmental Economics and Management, Vol. 67, No. 1, 2014, pp. 58-70.

[32] PORDATA. Average monthly basic remuneration of employees: total and by sex. http://www.pordata.pt/en/Municipalities/Average+monthly+basic+remuneration+of+empl oyees+total+and+by+sex-235. Accessed July 12, 2017.

[33] EUROSTAT. Wages and labour costs. http://ec.europa.eu/eurostat/statisticsexplained/index.php/Wages_and_labour_costs. Accessed July 12, 2017.

[34] Fliege, J., and I. F. Vaz. A Method for Constrained Multiobjective Optimization Based on SQP Techniques. SIAM Journal on Optimization, Vol. 26, No. 4, 2016, pp. 2091-2119.

[35] HCM. The Highway Capacity Manual. Transportation Research Board, Washington, DC, 2010. 